Fetal Diagnosis and Therapy

\title{
Fetal Cardiac Function: Technical Considerations and Potential Research and Clinical Applications
}

\author{
Fatima Crispi Eduard Gratacós \\ Department of Maternal-Fetal Medicine, Institut Clínic de Ginecologia, Obstetrícia i Neonatologia, \\ Hospital Clinic - Institut d'Investigacions Biomèdiques August Pi i Sunyer, University of Barcelona, and \\ Centro de Investigación Biomédica en Red en Enfermedades Raras, Barcelona, Spain
}

\section{Key Words}

Fetal cardiac function - Echocardiography - Doppler •

Strain - 4DSTIC

\begin{abstract}
Fetal echocardiography was initially used to detect structural anomalies but has more recently also been proposed to assess fetal cardiac function. This review summarizes technical issues and limitations in fetal cardiac function evaluation, as well as its potential research and clinical applications. Functional echocardiography has been demonstrated to select high-risk populations and to be associated with outcome in several fetal conditions including intrauterine growth restriction, twin-to-twin transfusion syndrome, maternal diabetes, and congenital diaphragmatic hernia. Fetal heart evaluation is challenging due to the smallness and high heart rate of the fetus and restricted access to the fetus far from the transducer. Due to these limitations and differences in cardiac function which are related to fetal maturation, cardiovascular parameters should be validated in the fetus and used with caution. Despite these precautions, in expert hands and with appropriate ultrasound equipment, evaluation of cardiac function is feasible in most fetuses. Functional fetal echocardiography is a promising tool that
\end{abstract}

may soon be incorporated into clinical practice. Research is warranted to further refine the contribution of fetal cardiac assessment to the diagnosis, monitoring, or prediction of outcomes in various fetal conditions.

Copyright $\odot 2012$ S. Karger AG, Basel

\section{Importance of Fetal Cardiac Function}

Fetal echocardiography was initially employed to detect structural anomalies [1], but its use in fetal cardiac function assessment has recently been proposed [1-5]. Fetal cardiac dysfunction may be due to an intrinsic myocardial disease or to a secondary adaptive mechanism. The latter is particularly important because the heart seems to be a central organ in the fetal adaptive response to a variety of insults [5-8]. Consequently, assessment of fetal cardiac function may be helpful in the diagnosis or monitoring of several fetal conditions [4-8]. In addition, given the substantial evidence indicating the occurrence of programming of adult cardiovascular disease in fetal life [9], cardiac function assessment might help to predict perinatal and long-term cardiovascular outcomes.

Evaluating fetal cardiac function is particularly challenging $[1,2]$. There are obvious difficulties in trying to

\section{KARGER}

Fax +4161306 1234

E-Mail karger@karger.ch

www.karger.com
(C) 2012 S. Karger AG, Basel

$1015-3837 / 12 / 0322-0047 \$ 38.00 / 0$

Accessible online at:

www.karger.com/fdt
Dr. Fatima Crispi

Department of Maternal-Fetal Medicine, Institut Clínic de Ginecologia,

Obstetrícia i Neonatologia, Hospital Clinic, University of Barcelona

ES-08028 Barcelona (Spain)

Tel. +34932279333,E-Mail fcrispi@ clinic.ub.es 
measure cardiac function in a small, moving, and changing patient, which are discussed in detail in the next section. An additional challenge is that fetal cardiac dysfunction is essentially subclinical [6-8]. Fetuses rarely go into cardiac failure, and when they do, the outcome is generally dire, with very few exceptions [4-8]. The results of cardiac examination in most fetuses in which cardiac function is of interest will be completely normal by child or adult cardiology standards. Thus classical indices used to determine the existence of cardiac failure in postnatal life are of little use in fetuses. Fortunately, adult cardiology has substantially developed in the last few years and a variety of new methods able to identify extremely subtle changes in cardiac function are now available [10]. Implementation of these technologies in the fetus is far from straightforward, but these advances have already shown highly promising results [11-14]. More detailed evaluation of cardiac function will allow new pathophysiological insights into a number of fetal conditions and possibly new clinical applications. We believe that a well-developed field of knowledge and specialization in fetal cardiac function in the course of the next 5-10 years can realistically be envisioned.

In this review we provide a very brief overview of currently available techniques to measure fetal cardiac function, the technical challenges and precautions required for its evaluation, and a noncomprehensive summary of the available data on fetal cardiac assessment in a variety of fetal conditions.

\section{Pathophysiological Basis of Fetal Cardiac Dysfunction}

The primary function of the heart is to eject blood in order to provide adequate perfusion of organs [15]. The heart achieves this function by contracting its muscular walls around a closed chamber to generate sufficient pressure to eject blood from the ventricle through the aortic/pulmonary valve and into the aorta/pulmonary artery (systole). Adequate filling of the ventricle from the atria (diastole) is also essential $[15,16]$. To maintain normal cardiac function, both systolic and diastolic processes must be preserved and time events must occur in a synchronized manner.

\section{Cardiac Cycle in Normal Conditions}

The normal cardiac cycle involves five major phases [15]. The first phases, considered together as the diastolic or ventricular filling stage, involve movement of blood from the atria into the ventricles [15]. The next phases, or systolic period, involve the movement of blood from the ventricles to the aorta and the pulmonary artery. The phases are as follows:

(1) Isovolumetric relaxation phase: diastole starts after aortic/pulmonary valve closure with an isovolumetric relaxation period. While the myocardium starts to relax no blood enters or ejects from the ventricles and the intraventricular pressure drops.

(2) Early diastole: when ventricular pressure lowers the atrial pressure, the filling phase starts with the mitral/ tricuspid valve opening and blood from the atria filling the ventricle in a passive manner.

(3) Atrial contraction period: the atria contract and complete the filling of the ventricle (late diastole).

(4) Isovolumetric contraction phase: systole is started by contraction of cardiomyocytes, which increases intraventricular pressure. This increase in pressure then opens the aortic/pulmonary valve (isovolumetric contraction time) while there is no change in volume.

(5)Ejection period: finally, when the ventricular pressure has increased sufficiently to open the aortic/pulmonary valves, the myocardium starts to deform and the blood is ejected from the ventricle.

These main components of the cardiac cycle define the main features of cardiac blood flow movement and myocardial motion and deformation [15-18].

\section{Definition of Heart Failure, Cardiac Dysfunction, and Remodeling}

Heart failure is defined as the inability of the heart to supply sufficient blood flow to meet the body's needs [19]. This is usually a late event that can be easily recognized by cardiomegaly, atrioventricular insufficiency, and fetal hydrops [4]. Heart failure can also be quantified by measuring a significant decrease in cardiac output or ejection fraction $[4,19]$.

However, in the initial stages of an insult, the heart usually manages to adapt and there is a long subclinical period of cardiac dysfunction before end-stage heart failure [4-6]. During this period of cardiac adaptation, changes in cardiac function, as well as in the heart's shape and size, can be measured. These changes are the heart's attempt to adapt to the insult, a process known as cardiac remodeling [20].

\section{Determinants of Fetal Cardiac (Dys-)function}

Changes in cardiac function and shape will depend mainly on the causal insult but are also determined by myocardial contractility, fiber orientation, tissue elastic- 
ity, heart geometry, segment interaction, loading conditions, electrical activation, and myocardial perfusion [10]. In the fetal heart, myocardial maturation and fetal blood circulation are also critical factors [21]. The most important determinants of fetal cardiac function are discussed below.

\section{Myocardial Contractility}

Myocardial contractility is the intrinsic ability of cardiac muscle to develop force for a given muscle length [15, 16] and may be affected by genetic deposition to cardiac diseases or by hypoxia $[10,16]$. Myocardial contractility essentially conditions myocardial motion and deformation during systole $[10,16]$. If the velocities measured at all points within a moving object are the same, then the object will be described as having motion [10]. If, on the other hand, different points within a moving object are moving at different velocities, then the object will exhibit deformation [10] and alter its shape:

- Myocardial motion is defined as the distance covered by one point over a certain period of time and is determined by displacement (distance) and velocity (distance divided by time).

- Myocardial deformation is defined as the change in the length/thickness of a segment (two points) and is determined by strain (percentage of change) and strain rate (velocity of segment change).

When myocardial fibers contract, all segments deform and then the heart's base moves toward the apex to eject blood [10]. Global longitudinal myocardial motion is usually measured at the mitral/tricuspid annulus as this fibrose area (with no intrinsic capacity for deformation) reflects the motion of all myocardial segments. Conversely, myocardial deformation should be assessed in a specific myocardial segment reflecting regional function.

\section{Fiber Orientation}

Myocardial contraction is a complex three-directional motion involving longitudinal contraction, radial contraction, and rotation (circumferential axis) [16]. These components are mainly determined by the complex geometry of myocardial fibers and muscle band orientation $[22,23]$.

- Longitudinal motion consists of the movement of fibers from the apex to the base of the heart and is mainly determined by endocardial longitudinal fibers, which are those farthest from the epicardial blood supply and consequently the most sensitive under milder degrees of hypoxia. Therefore, longitudinal motion usually becomes abnormal in the very early stages of cardiac dysfunction $[10,11,16]$.

- Radial motion is perpendicular to the epicardium and is determined by radial fibers mainly located in the mid part of the ventricular wall. Radial motion usually becomes abnormal in the late stages of fetal deterioration $[10,16,19]$.

- The circumferential axis is perpendicular to both the longitudinal and the radial axes. In the left ventricle myocardial wall, the geometry of the myofibers changes smoothly from a right-handed helix in the subendocardium to a left-handed helix in the subepicardium such that the angle of the helix varies continuously from positive at the endocardium to negative at the epicardium $[22,23]$. Therefore, the base and apex of the left ventricle rotate in opposite directions, leading to the twisting motion being described as 'the wringing of a linen cloth to squeeze out the water'. Rotation and twisting have been shown to become abnormal in the very early stages of cardiac dysfunction [24]. However, very few studies have successfully assessed rotation in utero, and therefore its utility in fetal life remains to be elucidated [25].

\section{Changes in Myocardial Maturation during in utero \\ Development}

During gestation, maturational changes occur within the myocardium leading to changes in elasticity and contractility throughout the pregnancy [26]. Once the structural details have been organized during the embryonic period, the fetal heart continues to grow by cell division until birth, and continued growth thereafter is due to cell enlargement [26]. The density and compaction of myofibrils increases particularly in early pregnancy, but contractility and elasticity continue to improve during the second half of pregnancy [27]. Changes in myocardial maturation should be taken into account when evaluating and interpreting fetal cardiac function.

Ventricular Loading

Volume and pressure loading conditions will determine cardiac function [10]:

- Preload is the muscle length prior to contractility and is dependent on ventricular filling or blood volume in end-diastole $[15,16]$. The most important determining factor for preload is venous return. Volume overload [e.g. due to fetal anemia, twin-to-twin transfusion syndrome (TTTS), valve leakage, etc.] will mainly lead to heart dilatation to help the heart manage the increased blood volume more efficiently [20]. 
- Afterload is the tension (or the arterial pressure) against which the ventricle must contract and depends on the maximum tension of the myocardial muscle mass in end-systole $[15,16]$. Afterload for the left ventricle is determined by aorta pressure, while afterload for the right ventricle is determined by pulmonary artery pressure. Pressure overload (e.g. due to valvular stenosis or TTTS) will mainly lead to myocardial hypertrophy in order to increase the contractile mass to overcome the elevated afterload [20].

Particularities of Fetal Circulation

In contrast to postnatal life, the fetal systemic circulation is fed from the left and right ventricles in parallel, but with a small proportion of the right output being spared for the lungs [21]. The well-oxygenated blood is directed from the umbilical vein through the ductus venosus (DV) across the inferior vena cava, through the foramen ovale, left atrium, and ventricle and up the ascending aorta to join the low oxygenated blood in the descending aorta. Deoxygenated blood from the superior and inferior vena cava is directed through the right atrium and ventricle, pulmonary trunk, and ductus arteriosus.

Additionally, the three shunts - DV, ductus arteriosus, and foramen ovale - are essential distributional arrangements, making fetal circulation a flexible and adaptive system for intrauterine life [21]. The hemodynamic properties and functional ranges of these shunts are important determinants of the development of the fetal heart and circulation during the second and third trimesters. Understanding the particularities of fetal circulation is essential for adequate comprehension of fetal cardiac function changes in normal and pathological conditions.

\section{Main Techniques and Indices Used to Assess Fetal Cardiac Function}

Traditionally, fetal cardiac function was assessed by measuring blood flow through conventional Doppler or cardiac morphometry in 2D or M-mode. More recently, direct assessment of myocardial motion and deformation has been proposed using tissue Doppler imaging (TDI) and $2 \mathrm{D}$ speckle tracking imaging $[10,28,29]$. Lately, $4 \mathrm{D}$ spatiotemporal image correlation (STIC) has also been proposed to more accurately evaluate cardiac dimensions and volumes [30]. A detailed list of the most common techniques used in the fetus is provided in table 1 and described below.

\section{Conventional Doppler}

As the primary function of the heart is to eject blood in order to provide adequate perfusion of organs, blood flow assessment is a common approach to evaluate fetal cardiac function [1, 31]. Conventional Doppler allows blood outflow (systole) and inflow (diastole) in the heart, as well as time events, to be evaluated:

- Doppler measurement of flow through the outflow tracts reflects systolic function. This measurement can be multiplied by the area of the outflow tracts to calculate the stroke volume, the amount of blood ejected per heart beat [15]. Combining this information with the fetal heart rate allows cardiac output (volume per minute) to be estimated, which should normally be expressed as the cardiac index (cardiac output adjusted by fetal weight) $[15,31]$. Cardiac output is a classical parameter to assess cardiac function but only becomes abnormal in the very late stages of deterioration when the heart fails to adapt and insufficient blood is ejected to meet organ requirements [31].

- The main Doppler indices used to evaluate diastolic function are the early distolic filling/atrial contraction) E/A ratios and precordial vein pulsatility indices $[1,18,31]$. Doppler allows evaluation of the blood flow filling the ventricle, which typically has a biphasic pattern reflecting $\mathrm{E}$ and $\mathrm{A}$. Calculation of the $\mathrm{E} / \mathrm{A}$ ratio essentially reflects ventricular relaxation [19] but this parameter is of little use in fetal life as it is strongly affected by respiratory and corporal movements, and a high fetal heart rate usually leads to temporarily fused $\mathrm{E} / \mathrm{A}$ waves $[2,3]$. Another important limitation of this ratio is that impaired relaxation can be reflected by an increased, decreased, or pseudo normal value, hampering interpretation [19]. Diastolic function can also be indirectly evaluated with Doppler assessment of the precordial veins, which reflect pressure changes in the right atrium and indirectly provide information on diastolic function of the right heart $[2,3]$. The DV is the most commonly used vessel in fetal medicine as it is known to reflect impaired relaxation and has been used in clinical practice as an early marker of disease $[32,33]$.

- Doppler is usually used to assess blood flow but can also be used to calculate time periods [31]. Of great interest are isovolumetric contraction and relaxation times, defined as the time elapsed from the start of contraction/relaxation and the closure/opening of the outflow valve, respectively. These periods, particularly the isovolumetric relaxation time (IRT), become abnormal in the very early stages of dysfunction, reflect- 
Table 1. Most commonly used systolic and diastolic parameters to assess fetal cardiac function

\begin{tabular}{|c|c|c|}
\hline Parameter & Definition & Techniques \\
\hline \multicolumn{3}{|l|}{ Systolic function } \\
\hline \multicolumn{3}{|l|}{ Blood volume estimation } \\
\hline Ejection fraction & $\begin{array}{l}\text { Fraction of blood ejected from the ventricle with } \\
\text { each heart beat }\end{array}$ & 2D, M-mode, 2D speckle tracking \\
\hline Cardiac output & $\begin{array}{l}\text { Volume of blood being pumped by the ventricle } \\
\text { per minute }\end{array}$ & 2D, conventional Doppler, STIC \\
\hline Annular displacement & $\begin{array}{l}\text { Distance of the movement of the atrioventricular } \\
\text { valve annulus }\end{array}$ & M-mode or 2D speckle tracking \\
\hline Systolic annular peak velocity & $\begin{array}{l}\text { Speed of movement of the atrioventricular valve } \\
\left.\text { annulus in systole ( } S^{\prime}\right)\end{array}$ & Spectral or color TDI \\
\hline \multicolumn{3}{|l|}{ Myocardial deformation } \\
\hline Strain & $\begin{array}{l}\text { Amount of deformation (change in length of a } \\
\text { myocardial segment from its original length) }\end{array}$ & $\begin{array}{l}\text { Color TDI or } 2 \mathrm{D} \text { speckle tracking } \\
\text { imaging }\end{array}$ \\
\hline \multicolumn{3}{|l|}{ Diastolic function } \\
\hline $\begin{array}{l}\text { Precordial vein blood flow patterns } \\
\text { (DV and others) }\end{array}$ & $\begin{array}{l}\text { Pattern of blood in precordial veins during atrial } \\
\text { contraction that indirectly reflects cardiac } \\
\text { compliance }\end{array}$ & Conventional Doppler \\
\hline $\mathrm{E} / \mathrm{A}$ ratio & $\begin{array}{l}\text { Ratio between early }(\mathrm{E}) \text { and late }(\mathrm{A}) \text { ventricular } \\
\text { filling velocity }\end{array}$ & Conventional Doppler \\
\hline Diastolic annular peak velocities & $\begin{array}{l}\text { Speed of movement of the atrioventricular valve } \\
\text { annulus in early (E') and late (A') diastole }\end{array}$ & Spectral or color TDI \\
\hline E/E’ ratio & $\begin{array}{l}\text { Transmitral-to-mitral annular diastolic velocity } \\
\text { ratio }\end{array}$ & Conventional Doppler and spectral TDI \\
\hline IRT & $\begin{array}{l}\text { Time between closure of the aortic valve and } \\
\text { opening of the mitral valve }\end{array}$ & $\begin{array}{l}\text { Conventional Doppler or spectral/color } \\
\text { TDI }\end{array}$ \\
\hline
\end{tabular}

STIC = Spatiotemporal image correlation; TDI = tissue Doppler imaging; $I R T=$ isovolumetric relaxation time; $\mathrm{MPI}=$ myocardial performance index.

ing an increase in the time required to properly relax the myocardium. Time events can be displayed individually or as a composite parameter, such as the myocardial performance index (MPI), which takes several systolic and diastolic time events into account $[34,35]$. The MPI is considered a marker of global cardiac function and it has been shown to be a highly sensitive parameter of dysfunction [36, 37].

\section{M-Mode}

M-mode techniques are traditionally used in a transverse cardiac view to measure the difference in end-systolic and end-diastolic ventricular diameter and to calcu- late ejection fraction by applying the Teicholz formula $[30,38]$. Ejection fraction is defined as the percentage of blood ejected in each heart cycle [38]. Although ejection fraction is the essential parameter characterizing heart failure in adulthood [19], it is usually altered only in the late stages of deterioration as it mainly reflects radial function [30, 39].

M-mode can be also applied in the long axis of the heart to evaluate tricuspid and mitral annular displacement, which have been proposed as sensitive markers of cardiac dysfunction as they reflect global longitudinal function $[11,40]$. 
Table 2. Summary of most important limitations of fetal cardiac function assessment for each technique

\begin{tabular}{|c|c|c|c|c|c|}
\hline & M-mode & $\begin{array}{l}\text { Conventional } \\
\text { Doppler }\end{array}$ & $\begin{array}{l}\text { Tissue } \\
\text { Doppler }\end{array}$ & $\begin{array}{l}\text { 2D speckle } \\
\text { tracking }\end{array}$ & 4D STIC \\
\hline Fetal position & + & ++ & +++ & + & + \\
\hline Fetal corporal and respiratory movements & + & ++ & +++ & +++ & +++ \\
\hline Changes throughout gestation - normalization & + & + & + & + & + \\
\hline Fetal heart size & + & ++ & ++ & ++ & + \\
\hline High fetal heart rate - frame rate acquisition & + & ++ & +++ & +++ & + \\
\hline Impossibility of ECG & - & - & +++ & +++ & - \\
\hline Lack of validation in utero & + & + & +++ & +++ & ++ \\
\hline
\end{tabular}

\section{Tissue Doppler Imaging}

While conventional echocardiographic techniques are based on blood flow, TDI uses frequency shifts in ultrasound waves to calculate myocardial velocity, which is characterized by a lower velocity and a higher amplitude $[17,41]$. TDI can be applied online to evaluate annular or myocardial velocities. Offline TDI analysis also allows deformation parameters (strain and strain rate) to be assessed:

- Peak velocities evaluated at the mitral or tricuspid annulus reflect global systolic (S') or diastolic (E' and A') myocardial motion and have been demonstrated to be an early and sensitive marker of cardiac dysfunction $[42,43]$.

- Peak systolic strain and strain rate assessed at each myocardial segment provide information on myocardial deformation and interaction with neighboring segments [17]. These parameters are also early markers of cardiac dysfunction [42].

Although TDI may provide valuable information on global and regional myocardial motion and deformation, this technique should be used with caution in the fetal heart as it has several major limitations, as described below [28].

\section{D Speckle Tracking}

Recent reports have described the use of non-Doppler technology. 2D speckle tracking techniques allow myocardial deformation to be quantified by using frame-byframe tracking of bright myocardial areas (speckles) [10]. $2 \mathrm{D}$ speckle tracking requires post-processing and off-line analysis of 2D images and allows myocardial strain and strain rate to be measured. Despite its potential advantages, this is a recent technique that still requires validation for use in the fetal heart $[29,44]$.

\section{D Spatiotemporal Image Correlation}

$4 \mathrm{D}$ STIC permits 3D reconstruction of the fetal heart over time. This technique is based on a sweep (volume data set) of the fetal heart containing a complete reconstructed cardiac cycle. From this saved volume, any target region of interest can be obtained at any stage of the cardiac cycle $[3,30]$. 4D STIC has been proposed to measure ventricular volumes that allow more accurate estimation of the cardiac output and ejection fraction. The off-line analysis also allows mitral/tricuspid annulus displacement to be assessed. 4D STIC is a promising technique that requires further studies to improve its applicability in fetal cardiac function assessment $[3,30]$.

The most suitable parameters for assessing fetal cardiac function will mainly be determined by the cause of the dysfunction. Abnormal values of ejection fraction or cardiac output are usually found in the late stages of deterioration, and therefore more sensitive parameters have been proposed for earlier diagnosis and monitoring of fetal cardiac dysfunction. In most cases of cardiac dysfunction, diastolic parameters (such as DV or IRT) are the first to be altered, reflecting impaired relaxation and compliance due to a stiffer or less effective heart. Similarly, parameters reflecting longitudinal function (such as annular displacement or velocities) are typically affected in the early stages as compared to radial function (such as ejection fraction).

\section{Technical Considerations when Measuring Cardiac Function in the Fetus}

Fetal heart evaluation is challenging due to the smallness of the fetal heart, the high heart rate, and limited access to the fetus far from the transducer. Fetal echocardiography requires specific training and expertise to ac- 
Table 3. Summary of the most important fetal cardiac function parameters proposed in clinical practice

\begin{tabular}{|c|c|c|c|}
\hline Fetal condition & Mechanism & Clinical applicability & Future research \\
\hline Congenital heart disease & $\begin{array}{l}\text { Intrinsic myocardial disease together } \\
\text { with volume and } \\
\text { pressure overload }\end{array}$ & $\begin{array}{l}\text { First-trimester DV to predict structural } \\
\text { heart disease } \\
\text { Cardiovascular criteria (mitral inflow } \\
\text { and qualitative ventricular contractility) } \\
\text { [56] for valvuloplasty in aortic stenosis } \\
\text { Systolic and diastolic function for the } \\
\text { differential diagnosis of } \\
\text { cardiomyopathies }[58,59]\end{array}$ & $\begin{array}{l}\text { First-trimester tricuspid regurgitation to } \\
\text { predict structural heart disease } \\
\text { Cardiovascular score to predict perinatal } \\
\text { mortality [52] } \\
\text { Annular peak velocities to predict long- } \\
\text { term cardiovascular outcome in aortic } \\
\text { stenosis [57] } \\
\text { Strain to predict outcome }[29,55]\end{array}$ \\
\hline Maternal diabetes & $\begin{array}{l}\text { Hypertrophic cardiomyopathy due to } \\
\text { hyperglycemia }\end{array}$ & & $\begin{array}{l}\text { Cardiac morphometry and function to } \\
\text { predict long-term cardiovascular } \\
\text { outcomes }\end{array}$ \\
\hline Placental insufficiency & $\begin{array}{l}\text { Chronic hypoxia together with } \\
\text { volume and pressure overload }\end{array}$ & $\begin{array}{l}\text { DV to monitor and predict short-term } \\
\text { outcomes in early FGR }\end{array}$ & $\begin{array}{l}\text { MPI to predict perinatal mortality in } \\
\text { early FGR } \\
\text { MPI and annular peak velocities } \\
\text { measured by TDI to diagnose and } \\
\text { monitor late FGR }\end{array}$ \\
\hline TTTS & $\begin{array}{l}\text { Hypertrophic cardiomyopathy in the } \\
\text { recipient due to volume and pressure } \\
\text { overload }\end{array}$ & $\begin{array}{l}\text { DV atrial flow in the recipient for } \\
\text { staging TTTS (Quintero staging) }\end{array}$ & $\begin{array}{l}\text { CHOP score to characterize } \\
\text { cardiovascular dysfunction in the } \\
\text { recipient }\end{array}$ \\
\hline $\begin{array}{l}\text { Congenital diaphragmatic } \\
\text { hernia }\end{array}$ & $\begin{array}{l}\text { Left heart underdevelopment } \\
\text { secondary to cardiac compression }\end{array}$ & & $\begin{array}{l}\text { MPI to predict short- and long-term } \\
\text { outcomes }\end{array}$ \\
\hline Trisomy 21 & Intrinsic myocardial abnormality & $\begin{array}{l}\text { First-trimester DV to predict structural } \\
\text { heart disease }\end{array}$ & $\begin{array}{l}\text { First-trimester DV, tricuspid } \\
\text { regurgitation, MPI, and shortening } \\
\text { fraction to predict structural heart } \\
\text { disease }\end{array}$ \\
\hline
\end{tabular}

DV = Ductus venosus; STIC = spatiotemporal image correlation; MPI = myocardial performance index FGR = fetal growth restriction; TTTS = twin to-twin transfusion syndrome; TDI = tissue Doppler imaging.

quire images and interpret the results. Several limitations should be taken into account when assessing fetal cardiac function (table 3). These limitations are particularly important in techniques requiring offline analysis (4D STIC, color TDI, and 2D speckle tracking).

\section{Fetal Position, Movement, and Size}

Several intrinsic particularities of the fetus such as its position, movements, and small size require expertise to acquire adequate images and may sometimes hamper complete evaluation. The fetus lies far down in the maternal abdomen and thus maternal adiposity, oligoamnios, or an anterior placenta may interfere with image quality. Fetal position changes constantly, requiring different angles to view the fetal heart. Optimal viewing can be impossible if the fetal spine is persistently in an anterior position, while evaluation of longitudinal or radial motion requires an apical/basal or transverse view, respectively. Both conventional and tissue Doppler are critically affected by the angle of acquisition, which should be as close to 0 as possible $[17,38]$. Other techniques such as 4D STIC or M-mode are less angle dependent but a good angle is still required to obtain reliable results. Fetal corporal and respiratory movements may also interfere with the quality of acquisition. Additionally, the fetal heart is much smaller than the adult heart and varies with gestational age. Therefore, normality ranges throughout pregnancy are always required to calculate $\mathrm{z}$-scores and standardize measurements. Some fetal conditions many affect heart size (e.g. leading to cardiomegaly) and therefore reference values adjusted by heart size or specific fetal biometries may be necessary to correctly adjust parameters that strongly depend on myocardial size (such as annular displacement or myocardial velocities) [45]. The smallness of the fetal heart also reduces the accuracy of estimates of cardiac or vessel dimensions. This consideration is particularly important in parameters estimated on the basis of formulas that include several measurements (e.g. cardiac output), which show a relatively wide variability as the error induced by one inaccurate dimen- 
sion is multiplied in the final calculation [31]. Furthermore, heart size strongly limits any attempt to differentially evaluate the endocardial and epicardial layers within the myocardium, which is too thin to be assessed separately. All of these limitations warrant specific training and a critical mentality to properly acquire and interpret functional fetal echocardiography [1].

\section{Fetal Heart Rate and Frame Rate Requirements}

Proper acquisition, processing, and interpretation are even more critical in techniques requiring offline analysis, such as TDI or 2D speckle tracking [28, 29]. Software tools for offline analysis of deformation were initially designed for the adult heart with a low heart rate, fixed position, and electrocardiographic (ECG) co-registration [28, 29, 46]. Therefore, the intrinsic characteristics of the fetal heart may hamper correct performance of the algorithms and therefore limit their reliability. Because of the restricted access to the fetal heart far down in the maternal abdomen, fetal ECG co-registration is impossible. ECG co-registration is critical to identify time events and, for example, to be able to assess postsystolic events [46]. ECG co-registration is also mandatory for the correct functioning of offline cardiac software tools. Recent reports have proposed the use of dummy ECG by manual indication of time events based on the underlying M-mode [13] or 2D images [14] in order to improve offline analysis of both TDI and 2D speckle tracking. Additionally, while the required frame rate for proper offline analysis is reasonably well defined in the adult heart [17], a higher frame rate would probably be necessary for the fetal heart (as the heart rate is about 2-3 times faster in fetuses than in adults) but optimal values remain to be defined. Poor quality acquisitions with a low frame rate or lack of ECG co-registration may lead to incorrect results. A clear example of inconsistent data is the disagreement in reports on longitudinal strain changes throughout gestation, which were described as increasing in the first studies performed with low frame rate acquisitions but were shown to decrease by recent studies using more appropriate methodology [12, 13, 47]. Although recent reports using acquisitions at a high frame rate and dummy ECG have improved the feasibility of these techniques [12-14], several limitations such as the variable view of the fetal heart and the smallness of the heart (with potentially insufficient myocardium to allow analysis in early gestational ages) remain to be overcome.

\section{Differences between Fetal and Postnatal Life}

Most echocardiographic techniques are derived from parameters previously developed and validated in the adult heart. However, unlike in the adult heart, changes in fetal cardiomyocyte maturation (myocardium stiffness and intrinsic contractility) and loading occur during gestation and within the myocardium $[26,27]$. Additionally, the fetal circulation pattern differs from that in the adult, with a predominant right heart and both circulations being connected [21]. This pattern may also change during pregnancy, which may hamper the understanding of cardiac adaptation due to different insults (volume or pressure overload, hypoxia, cardiac compression, etc.) in utero. Therefore, all of these changes should be taken into account when interpreting the results of fetal echocardiography.

\section{Lack of Validation of Techniques in the Fetal Heart}

Because invasive study of the fetal circulation is not feasible, most of the techniques used in fetal functional echocardiography have not been validated, limiting their interpretation. Additionally, there are discrepancies in the literature on many cardiac function parameters regarding methodology, normal values, and interpretation. For example, measurement of MPI using either blood flow or valve clicks as landmarks leads to different normality values [48]. Another example is the Teich holz formula for ejection fraction, which assumes a normal adult heart geometry, which the fetal heart cannot meet [38]. Moreover, the E/E' ratio has been demonstrated to correlate with intracavitary pressure at end-diastole [49], but its significance in fetal life is unknown. Therefore, the results of fetal echocardiography should be critically evaluated, taking into account gestational age and the methodology used. Finally, TDI and 2D speckle tracking techniques have been validated for deformation analysis in the adult heart by experimental settings including sonomicrometry [17]. However, no validation studies using invasive procedures can be performed to ascertain the real strain and strain rate values in the fetal heart during the maturation process. Despite these limitations, recent reports have demonstrated that deformation can be assessed in a reproducible manner when the appropriate methodology is employed [12-14]. However, many studies do not properly describe the methodology used or acknowledge potential limitations. Critical reading of all studies on fetal cardiac function, particularly of those using new technologies, is mandatory before accepting their results and conclusions.

As described above, fetal cardiac function assessment may have major limitations and therefore any technique or parameter proposed for its assessment should follow several steps for validation before being incorporated into 
clinical practice. The first phase is to demonstrate feasibility and reproducibility in well-designed and conducted studies. Use of the proposed parameter following strict methodological criteria is also critical to ensure proper applicability. Then, the behavior of the parameter in normal fetal conditions (physiology), as well as in each clinical disease (pathophysiology), must be described before the technique or parameter can applied in clinical conditions.

\section{Research and Clinical Applications of Fetal Cardiac Function Assessment}

\section{Congenital Heart Disease}

First-Trimester Screening of Congenital Heart

Disease

Cardiac function assessment in the first trimester may help in the early detection of congenital heart disease. DV flow $[2,50]$ and tricuspid regurgitation [51] are associated with an increased prevalence of cardiac defects. Fetal nuchal translucency above the 95th percentile, DV atrial reversed flow, or tricuspid regurgitation are present in 35, 28 , and $33 \%$ of fetuses with cardiac defects, respectively, and in 5,2 , and $1 \%$ of those without cardiac defects [51]. A combination of these three markers may permit detection of about $50 \%$ of cardiac defects, with a false-positive rate of $8 \%[51]$.

Fetal Cardiac Function in Congenital Heart Disease

Evaluation of cardiac function in fetuses with congenital heart disease has been proposed to better understand the pathophysiology of these diseases, predict the perinatal outcome, and guide and monitor any in utero therapy. Huhta [4] proposed a cardiovascular score, including the presence of hydrops, cardiomegaly, abnormal myocardial function (measured as a monophasic inflow pattern, tricuspid/mitral regurgitation, or reduced shortening fraction), abnormal ductus venosus or umbilical artery or vein Doppler. This score showed a high sensitivity and specificity in identifying fetuses with cardiac defects at high risk of perinatal mortality [52]. These data paved the way for future studies incorporating newer techniques for the evaluation of cardiac function. However, various types of congenital heart disease show specific differences in volume and/or pressure load, as well as distinct degrees of cardiac remodeling and adaptation. Preliminary studies have evaluated the potential contribution of TDI and 2D speckle tracking techniques in congenital heart disease of various types [53-55]. Peak annular velocities, ventricular strain, and the left/right ventricular strain ratio have been proposed as prognostic markers in these entities [53-55]. Fetuses with left heart obstruction (hypoplastic left heart syndrome and critical stenosis of the aorta) show reduced left ventricular strain and left/right ventricular strain ratio values, while right ventricular values are maintained within the normal range [53-55]. In contrast, right heart defects such as Ebstein's anomaly lead to reduced longitudinal right ventricular strain with increased left/right ventricular strain ratio values [55]. Additionally, deformation parameters within normal ranges with a similar left/right ventricular strain ratio have been reported in other anomalies such as tetralogy of Fallot, double outlet right ventricle and atrial/ventricular septal defects $[54,55]$. The above mentioned findings suggest that specific cardiovascular profile scores adjusted for the type of cardiac defect might provide clinically useful information. Confirmation of this hypothesis requires further research with large samples.

\section{In utero Cardiac Intervention}

Fetal aortic balloon valvuloplasty improves the perinatal and postnatal outcome of critical aortic stenosis [56]. Monophasic mitral inflow and qualitative left ventricular dysfunction are included in the selection criteria to predict progression to hypoplastic left heart syndrome and eligibility for prenatal intervention [56]. Additionally, left ventricle diastolic dysfunction including TDI peak velocity assessment has been suggested as a prognostic marker of poor long-term outcome in these cases [57].

Differential Diagnosis of Cardiomyopathies

Assessment of fetal cardiac function has been proposed as a diagnostic and prognostic tool in fetal cardiomyopathies [58, 59]. Hypertrophic cardiomyopathy is characterized by increased ventricular wall thickness that leads to impaired relaxation together with systolic dysfunction (demonstrated by a decreased shortening fraction), present in almost half of all cases. In addition, most fetuses with dilated cardiomyopathy will have systolic dysfunction with or without chamber enlargement but without increased wall thickness. The presence of diastolic dysfunction is similar in both types of disease (about $60 \%$ of cases) including abnormal venous flows (umbilical vein pulsations and biphasic inferior vena cava flow), a decreased E/A ratio, and an increased IRT. Although the presence of systolic dysfunction and significant atrioventricular valve regurgitation are risk factors for mortality, diastolic dysfunction (particularly abnor- 
mal systemic venous flow patterns and umbilical venous pulsations) is considered the best predictor of perinatal mortality $[58,59]$.

\section{Maternal Diabetes}

Maternal hyperglycemia can have a substantial impact on fetal cardiovascular development, including structural defects [60] and myocardial hypertrophy. Maternal diabetes is the most common cause of fetal hypertrophic cardiomyopathy, which is characterized by an enlarged heart, increased shortening fraction and systolic longitudinal motion [61], thickening of the interventricular septum, and ventricular outflow obstruction. These changes occur in an otherwise structurally normal fetal heart in about a quarter of affected pregnancies [62]. The fetuses of diabetic mothers show signs of impaired relaxation (diastolic dysfunction), as measured by increased pulsatility in precordial veins [63-66], a lower E/A ratio [67], an increased IRT [67], increased diastolic annular peak velocities and E/E' ratio [7], and increased cord blood levels of atrial and B-type natriuretic peptide (ANP/BNP) and troponin [68]. Abnormalities are more evident in pregnancies with poorer glycemic control but still occur with strict metabolic control [60-66]. Cardiac hypertrophy and dysfunction persist postnatally in a proportion of these fetuses, leading to worse neonatal outcomes [69]. Additionally, increased cardiovascular risk factors have been described in the children of diabetic mothers [70]. As changes in cardiac function become apparent before there is ultrasonographic evidence of cardiac hypertrophy $[7,67]$, cardiac function parameters have been suggested as useful early predictors of outcomes in these pregnancies, but their utility has not yet been confirmed.

\section{Placental Insufficiency}

Fetal growth restriction (FGR), caused by placental insufficiency, affects up to $10 \%$ of all pregnancies and is a major cause of perinatal mortality and severe morbidity [42]. Early- and late-onset FGR are increasingly being recognized as distinct forms of the disease in view of their differences in incidence, pathophysiology, and natural history [43]. The heart is a central organ in fetal adaptive mechanisms to placental insufficiency, and cardiac dysfunction is recognized as being among the central pathophysiologic features of both early- and late-onset FGR [44-47].

\section{Early-Onset FGR}

Early FGR (<34 weeks' gestation) resulting from severe placental insufficiency affects less than $1 \%$ of deliv- eries and is known to be among the main causes of perinatal mortality and morbidity [71]. Prediction of mortality and morbidity is critical for the clinical management of these fetuses [32]. FGR illustrates how cardiac dysfunction in the fetus is largely subclinical and requires sensitive methods for its identification [6]. Thus, earlier reports suggested that systolic dysfunction appeared only in severely affected fetuses, because ejection fraction deteriorates only in the very late stages [72] and the cardiac output adjusted by fetal weight remains normal throughout disease progression [6, 73]. However, more recent studies using myocardial imaging techniques have demonstrated that systolic annular peak velocities are decreased from the very early stages of FGR, long before atrial flow in the DV becomes abnormal $[43,74]$. Additionally, fetuses with early FGR show signs of impaired relaxation (diastolic dysfunction) from the early stages of deterioration [6], as measured by increased pulsatility in precordial veins (particularly DV) $[6,32,75]$, higher E/A ratios $[6,32,74,76-78]$, increased IRT $[6,43,79]$, reduced diastolic annular peak velocities $[43,80]$, and increased cord blood levels of ANP and BNP [6, 81]. This decrease in longitudinal motion and impaired relaxation may be a fetal adaptive mechanism to the chronic hypoxia and volume/pressure overload of placental insufficiency.

Several cardiac parameters have been proposed as predictors of acidemia and adverse perinatal outcomes in early FGR $[32,75,81]$. Perinatal mortality in early FGR has been described as being associated with abnormal DV [32], increased MPI [82], and decreased annular peak velocities by TDI [74]. In a recent systematic review, DV emerged as a strong predictor of mortality, with a sensitivity ranging from 40 to $60 \%$ [83]. Although preliminary data suggested that, in addition to DV, MPI could help to predict perinatal mortality in early FGR [82], a recent multicenter study has not confirmed these results [84]. Thus, studies on the potential clinical value of cardiac function parameters in predicting the outcome and monitoring of early FGR in large prospective cohorts are warranted.

\section{Late-Onset FGR}

Small fetuses near term have long been considered to be constitutionally small with a good prognosis [85]. However, recent evidence suggests that a proportion of these fetuses represent true forms of late FGR with a mild degree of placental insufficiency (not reflected by umbilical artery Doppler) and poorer perinatal [86] and long-term results, including suboptimal neurodevelopment $[87,88]$ and a higher postnatal cardiovascular risk $[9,89,90]$, compared with normal weight newborns. Al- 
though few studies have evaluated cardiac function in late FGR fetuses, recent data suggest that these fetuses might also show features of cardiac dysfunction [91-93]. Increased cord blood levels of troponins have been demonstrated in a small proportion of later small-for-gestational-age newborns [91]. Additionally, more than $30 \%$ of late-onset small-for-gestational-age fetuses even with normal umbilical artery Doppler show increased values of MPI $[92,93]$ and decreased annular peak velocities [92]. Therefore, sensitive cardiovascular parameters may be useful to identify the subgroup of small fetuses at higher perinatal and long-term risk.

\section{FGR and Postnatal Cardiovascular Risk}

Postnatal persistence of cardiovascular remodeling has recently been demonstrated in a cohort of 5-year-old children who suffered early or late FGR [89]. FGR children show changes in cardiac shape (more globular morphology), subclinical cardiac dysfunction (increased heart rate and reduced stroke volume and myocardial peak velocities), and vascular remodeling (increased blood pressure and carotid intima media thickness). Both cardiac and vascular changes are present in early and late FGR, with a tendency toward worse results in early-onset cases. These data are in line with previous historic cohort studies [9] and animal models [90] demonstrating a strong association between small size at birth and increased adult cardiovascular mortality. These findings suggest that FGR induces primary cardiac changes, which could explain the increased predisposition to cardiovascular disease in adult life. An interesting hypothesis is that fetal cardiac function assessment might help to identify FGR cases at high cardiovascular risk later in life, therefore allowing timely preventive interventions.

\section{Twin-to-Twin Transfusion Syndrome}

TTTS complicates $10-15 \%$ of monochorionic twin pregnancies and is characterized by unbalanced chronic blood transfer from one twin, defined as the donor twin, to the other, defined as the recipient, through placental anastomoses [94]. Significant hemodynamic changes are commonly observed in both fetuses in TTTS including hypervolemia in the recipient and hypovolemia in the donor, resulting in chronic activation of the renin-angiotensin system and release of vasoactive factors, which leads to pressure overload in both fetuses [95].

\section{Prenatal Cardiac Function in TTTS}

Significant changes in fetal cardiac function despite a normal heart structure have also been reported. Most changes are described in the recipient, in which volume and pressure overload lead to cardiomegaly and hypertrophy, usually with impaired relaxation but preserved systolic function [96]. Volume overload is reflected by increased umbilical blood flow $[97,98]$ and ductus venosus pulsatility $[37,95,96]$, tricuspid and mitral insufficiency, cardiomegaly $[95,96,99,100]$, and increased levels of ANP and BNP [37, 101]. Pressure overload leads to cardiac hypertrophy in more than half of recipients $[95,96$, $100,102]$, usually with an increase in ejection fraction $[96,99]$. This cardiac hypertrophy explains the impaired relaxation and increased ventricular filling pressures that lead to reduced E/A ratios or a monophasic Doppler inflow profile $[37,96,103]$ together with increased E/E' ratios [102] and MPI (mainly due to an increased IRT) [37, $96,103,104]$. Ten to twenty percent of recipients also show some degree of right tract obstruction (pulmonary stenosis, dysplasia, insufficiency, or atresia) [37, 96]. Most studies report preserved systolic function until the end stages when ejection fraction can decrease in recipients. However, a recent study reported a reduced right ventricular systolic strain and strain rate in recipients [37], which supports the concept of subclinical systolic dysfunction from the early stages of TTTS. In contrast, most studies report no significant changes in the donor's cardiac function $[96,102]$ apart from arterial and venous (umbilical artery and vein and DV) Doppler changes, reflecting hypovolemic status [37].

The Children's Hospital of Philadelphia (CHOP) score has been proposed to assess severity in TTTS [5]. This score incorporates the donor's umbilical artery evaluation and assessment of cardiac hypertrophy, dilation, impaired systolic or diastolic function, atrioventricular valve regurgitation, pulmonary valve structural or Doppler abnormalities, and venous Doppler abnormalities in the recipient. A composite score of $0-20$ is generated, with 0 representing the best possible score and 20 indicating severe TTTS. However, this score has not been shown to be of clinical use as a diagnostic or prognostic marker in TTTS [96].

Several studies have evaluated the correlation between cardiac function and TTTS severity, demonstrating that cardiomegaly, systolic dysfunction, and right outflow tract obstruction are more prevalent in advanced Quintero stages $[98,102]$. However, cardiac changes may be present even in early Quintero stages as $20-60 \%$ of recipients in stages I-II may have cardiac hypertrophy, tricuspid regurgitation, or increased MPI or BNP or troponin T blood levels [44, 96, 102, 104]. Some authors have proposed cardiovascular scores to stratify the severity of 
TTTS [5], but cardiovascular function (parameter or score) has not been shown to be of clinical use as a diagnostic or prognostic marker in TTTS [96].

Treatment based on coagulation of placental anastomosis by fetoscopy improves cardiac function in recipients as measured by a decrease in DV-PI [37, 97], MPI, and the presence of tricuspid regurgitation and EA fusion [37, 96]. In contrast, donors may show transient signs of relative hypervolemia reflected by an increase in umbilical vein flow, DV-PI [37, 97], tricuspid regurgitation [37], and even hydrops [97] that usually regresses within 4 weeks [37].

\section{Postnatal Cardiac Function in TTTS}

Most studies report normal postnatal cardiac evaluation in TTTS pregnancies treated by fetoscopy [105], with the exception of some recipients with pulmonary stenosis requiring postnatal valvuloplasty $[95,106,107]$. However, a recent study evaluating TTTS survivors at school age has demonstrated reduced diastolic function in recipients and abnormal cardiac dimensions in some donors [108]. Persistent pulmonary hypertension after birth has also been described in some recipient twins [109]. Moreover, recipient twins show increased blood pressure levels already in the neonatal period $[110,111]$, while donors have lowered arterial distensibility $[112,113]$, which might be a response to the chronic activation of the renin-angiotensin system. Therefore, further studies to assess the cardiovascular outcome of twin survivors are warranted.

\section{Congenital Diaphragmatic Hernia}

Left heart underdevelopment $[8,114,115]$ is commonly observed in fetuses with congenital diaphragmatic hernia. This finding has been attributed to compression of the left atrium by herniated abdominal organs (mainly the liver), redistribution of fetal cardiac output, and/or low pulmonary venous return. Although left ventricular volumes are about one third smaller than in normal fetuses, cardiac shifting or dimensions do not predict postnatal outcome in fetuses with isolated left-sided congenital diaphragmatic hernia [116]. This finding is supported by the observation that cardiac dimensions are not related to significant changes in cardiac function (as measured by ejection fraction or MPI) [8] and by the fact that the growth of the heart generally catches up after surgical correction in the neonatal period and that cardiac size is normal in long-term survivors of isolated congenital diaphragmatic hernia [117].

However, recent data in children has shown that MPI, systolic/diastolic time, and plasma levels of BNP are able to predict neonatal mortality and the need for extracor- poreal membrane oxygenation [118-120]. Additionally, tracheal occlusion improves MPI by shortening the isovolumic contraction time interval [8]. Therefore, future studies are warranted to evaluate the potential value of cardiac function parameters to monitor and predict outcome in these fetuses.

\section{Miscellanea}

Several other fetal anomalies have been reported to be associated with cardiac dysfunction and are commonly due to heart compression, volume overload, or a direct insult to the myocardium.

Large intrathoracic masses such as a congenital cystic adenomatoid malformation with mediastinal deviation have been described as compressing the heart and affecting cardiac volume loading, sometimes leading to heart failure and hydrops $[121,122]$. Signs of diastolic dysfunction (increased E/A ratio and right MPI) and poor filling secondary to cardiac compression and a tamponade effect (cardiomegaly, reduced cardiac output, preserved ejection fraction, and increased reversal atrial contraction in the inferior vena cava) usually appear before hydrops is observed [121, 122].

Similarly, sacrococcygeal teratoma or arteriovenous malformations, characterized by high blood flow through the tumor (volume overload), can also lead to heart failure $[123,124]$. The inferior vena cava and the cardiac ventricles dilate due to increased venous return from the tumor, even though these fetuses typically maintain a normal shortening fraction as intrinsic contractility is not affected until the final stages. Similarly, a dilated superior vena cava and cardiomegaly develop in deteriorating fetuses with large cerebral arteriovenous malformations such as an aneurism of the vein of Galen. In both conditions, neonatal outcomes are poorer in fetuses that develop hydrops prior to delivery, and recognition of more subtle signs of cardiac failure may prompt antenatal intervention or delivery $[123,124]$.

Absence of the DV with extrahepatic shunt that directly connects umbilical vein flow with the heart causes volume overload that may lead to cardiomegaly, tricuspid regurgitation, heart failure, and hydrops in half of these cases $[125,126]$.

Lower urinary tract obstruction with massive bladder distension may cause vascular compression, leading to an increased cardiothoracic ratio, small pericardial effusion, ventricular hypertrophy, and diastolic dysfunction (altered E/A ratio and increased DV-PI) [127].

Fetal anemia leads to hyperdynamia, relative volume overload, and hypoxia, which may cause cardiomegaly, 
heart failure, and hydrops. Surviving children who received intrauterine transfusions show a reduction in left ventricular mass and atrial area with preserved ventricular function in childhood [128].

Acute parvovirus B19 infection in pregnancy may lead to severe anemia caused by the destruction of red blood cell precursors but may also be a result of hypoalbuminemia, hepatitis, myocarditis, and placentitis, which can culminate in cardiac failure and subsequent hydrops fetalis or fetal death [129]. Cardiac failure may be a result of severe anemia but may also be associated with myocarditis, which can cause arrhythmias or even cardiac arrest without evidence of anemia, cardiac failure, or hydrops $[129,130]$.

Preterm rupture of membranes, particularly in cases with intra-amniotic infection, is associated with changes in fetal cardiac function consistent with increased left ventricular compliance and systolic dysfunction measured as an increased E/A ratio [131, 132], shorter ejection time [133], and ventricular strain [132].

Cardiac function assessment in the first trimester may help in the early detection of trisomy 21 , as the presence of tricuspid regurgitation, atrial reversed flow in the DV, increased right E/A ratio and MPI, and shortening fraction and stroke volume are associated with Down syndrome even in the absence of structural heart defects [134]. Signs of cardiac dysfunction persist in the second and third trimester in cases of trisomy 21 [135].

\section{Fetal Programming of Cardiovascular Diseases}

It is well-known that cardiovascular diseases in adulthood undergo a long subclinical phase over decades, which may already start in childhood [136]. Aside from well-described lifestyle factors and a genetic predisposition, it is widely accepted that in a proportion of cases cardiovascular disease has its origins in prenatal life [9]. Any insult during in utero cardiac development may lead not only to cardiac dysfunction during fetal life but also to epigenetic changes that may persist postnatally leading to permanent cardiac remodeling [9]. Fetal programming of adult cardiovascular diseases occurs when a stimulus or an insult in the in utero environment during a sensitive period of cardiovascular development permanently alters cardiovascular structure and function. This concept was first described a quarter of a century ago by Barker et al. [9] who crystallized the concept of fetal programming and early origin of adult disease by suggesting that stress in utero, as manifested by a low birth weight and increases in the risk of cardiovascular disease and stroke in specific areas of England and Wales. A number of studies support that it might be explained in part by fetal metabolic programming leading to diseases associated with cardiovascular disease, such as obesity, diabetes mellitus, and hypertension [137]. However, several studies have also demonstrated that FGR conditions cardiac dysfunction in utero $[6,81]$ that persists postnatally [89], supporting the hypothesis of a primary cardiovascular programming. Apart from FGR, other fetal conditions such as maternal diabetes [69, 70], TTTS [113], or in vitro fecundation [138] have also been proposed as prenatal conditionings for fetal cardiovascular programming.

The importance of early identification and intervention in pediatric risk factors for cardiovascular disease is now well recognized [139]; however, FGR or other fetal conditions are not usually listed among the conditions presumed to increase cardiovascular risk in current consensus guidelines [139]. Physicians should routinely incorporate pregnancy information into the individual medical history. Prenatal identification of high-risk population permits proper monitoring and early intervention that could improve the cardiovascular health of thousands of children yearly.

\section{Conclusions}

Fetal cardiac function may be affected by a number of congenital or environmental anomalies [4-8]. Although research efforts have recently recognized the potential value of monitoring cardiac function for clinical management, most parameters are still in the research phase. The exception is DV, which is already being used in clinical practice for staging TTTS [94] or monitoring early FGR [32]. Another example is the integration of some cardiac function parameters (mitral inflow and myocardial contractility) into the inclusion criteria for fetal valvuloplasty in critical aortic stenosis [56, 57]. Additionally, some cardiac parameters have already shown a strong correlation with outcome and may soon be incorporated into clinical practice. For example, cardiac function assessment has proven utility in the differential diagnosis of cardiomyopathies $[58,59]$ or prediction of perinatal mortality in congenital heart disease [52]. Similarly, first-trimester DV and tricuspid regurgitation assessment has an additional predictive value for Down syndrome and congenital heart disease [51]. In addition, some cardiac parameters with high sensitivity such as MPI or annular peak velocities have shown promising results in monitoring and predicting outcomes in FGR $[79,84]$ or congenital diaphragmatic hernia [8]. Other promising parame- 
ters that have recently been proposed remain to be validated in fetal heart assessment. Conversely, cardiac function assessment does not have demonstrated utility in the staging or prognosis of TTTS [96].

Complete assessment and integration of the distinct components of systolic and diastolic function are crucial as no single simple test can fully evaluate fetal cardiac function. Several groups have suggested scoring systems $[4,5]$, which combine methods of assessment to provide a more global overview of cardiac function and which could be used as a prognostic marker or to define heart failure. Huhta [4] described a cardiovascular profile score that has been demonstrated to be useful in predicting the outcome of fetuses with hydrops [4] and congenital heart diseases [51]. Conversely, the CHOP score has not been shown to be clinically useful as a diagnostic or prognostic marker in TTTS $[5,96]$.

These scoring systems aim to standardize the current practice of multimodal assessment, which is partly based on subjective parameters such as grading ventricular dysfunction. Although scoring may be superior to single measurements in defining compromised cardiocirculatory function, there are still many limitations for the incorporation of the proposed scores in clinical practice. Scores need to be validated not only to predict perinatal mortality but also to predict morbidity and long-term outcomes. Many definitions of abnormal cardiac function need to be standardized. Cardiac function can be affected by various fetal abnormalities through volume or pressure overload, hypoxia, hyperglycemia, heart compression, direct myocardial damage, etc. Although disease-specific cardiovascular profile scores would most probably improve the predictive value for adverse outcome, constructing such a profile would be highly complex. Finally, the already proposed scores include traditional cardiac parameters, while new parameters such as MPI [36], annular peak velocities [43], or ventricular strain [44] have been demonstrated to be more sensitive in certain specific conditions. Therefore, studies to further evaluate the potential utility of recently proposed techniques and to define the best combination of parameters are warranted. New cardiovascular parameters should be incorporated with caution, taking into account all of the potential limitations of fetal echocardiography.

Despite these limitations, cardiac function can be adequately evaluated in most fetuses when appropriate expertise, equipment, and time are available. Many cardiac function parameters are sufficiently sensitive for selecting high-risk populations and predicting outcomes. Fetal cardiac function assessment is a promising tool that may soon be incorporated into clinical practice to diagnose, monitor, or predict outcomes in some fetal conditions. Thus, more research is warranted to further define specific protocols for each fetal condition that may affect cardiac function.

\section{Acknowledgements}

This study was supported by grants from Instituto de Salud Carlos III (PI11/00051) cofinanciado por el Fondo Europeo de Desarrollo Regional de la Unión Europea "Una manera de hacer Europa", Spain; Centro para el Desarrollo Técnico Industrial (cvREMOD 2009-2012) apoyado por el Ministerio de Economia y Competitividad y Fondo de inversión local para el empleo, Spain; Ministerio de Economia y Competitividad PN de I+D+I 20082011 (SAF2009-08815), Spain; Cerebra Foundation for the Brain Injured Child (Carmarthen, Wales, UK) and Thrasher Research Fund (Salt Lake City, Utah, USA).

\section{References}

1 Lee W, Allan L, Carvalho JS, Chaoui R, Copel J, DeVore G, Hecher K, Munoz H, Nelson T, Paladini D, Yagel S, ISUOG Fetal Echocardiography Task Force: ISUOG consensus statement: what constitutes a fetal echocardiogram? Ultrasound Obstet Gynecol 2008; 32:239-242.

2 Van Mieghem T, DeKoninck P, Steenhaut P, Deprest J: Methods for prenatal assessment of fetal cardiac function. Prenat Diagn 2009; 29:1193-1203.

-3 Godfrey ME, Messing B, Cohen SM, Valsky DV, Yagel S: Functional assessment of the fetal heart. Ultrasound Obstet Gynecol 2011; 39:131-144.
4 Huhta JC: Guidelines for the evaluation of heart failure in the fetus with or without hydrops. Pediatr Cardiol 2004;25:274286.

5 Rychik J, Tian Z, Bebbington M, et al: The twin-twin transfusion syndrome: spectrum of cardiovascular abnormality and development of a cardiovascular score to assess severity of disease. Am J Obstet Gynecol 2007; 197:392.e1-392.e8.

-6 Crispi F, Hernandez-Andrade E, Pelsers M, et al: Cardiac dysfunction and cell damage across clinical stages of severity in growthrestricted fetuses. Am J Obstet Gynecol 2008;199:254.e1-254.e8.
7 Hatém MA, Zielinsky P, Hatém DM, Nicoloso LH, Manica JL, Piccoli AL, Zanettini J, Oliveira V, Scarpa F, Petracco R: Assessment of diastolic ventricular function in fetuses of diabetic mothers using tissue Doppler. Cardiol Young 2008;18:297-230.

8 Van Mieghem T, Gucciardo L, Done E, et al: Left ventricular cardiac function in fetuses with congenital diaphragmatic hernia and the effect of fetal endoscopic tracheal occlusion. Ultrasound Obstet Gynecol 2009;34: 424-429. 
\$9 Barker DJ, Osmond C, Golding J, Kuh D, Wadsworth M: Growth in utero, blood pressure in childhood and adult life, and mortality from cardiovascular disease. BMJ 1989; 298:564-567.

10 Bijnens BH, Cikes M, Claus P, Sutherland GR: Velocity and deformation imaging for the assessment of myocardial dysfunction. Eur J Echocardiogr 2009;10:216-226.

-11 Gardiner HM, Pasquini L, Wolfenden J, Barlow A, Li W, Kulinskaya E, Henein M: Myocardial tissue Doppler and long axis function in the fetal heart. Int J Cardiol 2006;113:39-47.

-12 Matsui H, Germanakis I, Kulinskaya E, Gardiner HM: Temporal and spatial performance of vector velocity imaging in the human fetal heart. Ultrasound Obstet Gynecol 2011;37:150-157.

13 Willruth AM, Geipel AK, Fimmers R, Gembruch UG: Assessment of right ventricular global and regional longitudinal peak systolic strain, strain rate and velocity in healthy fetuses and impact of gestational age using a novel speckle/feature-tracking based algorithm. Ultrasound Obstet Gynecol 2011;37: 143-149.

14 Crispi F, Sepulveda-Swatson E, Cruz-Lemini M, Rojas-Benavente J, Garcia-Posada R, Dominguez JM, Sitges M, Bijnens B, Gratacós E: Feasibility and reproducibility of a standard protocol for 2D-speckle tracking and tissue Doppler based strain and strain-rate analysis of the fetal heart. Fetal Diagn Ther, in press.

15 Guyton AC, Hall JE: Textbook of Medical Physiology, ed 11. Philadelphia, Elsevier Saunder, 2006.

16 Bijnens B, Cikes M, Butakoff C, Sitges M, Crispi F: Myocardial motion and deformation - what does it tell us and how does it relate to function? Fetal Diagn Ther, in press.

17 Sutherland GR, Hatle L, Claus P, D'hooge J, Bijnens B: Doppler Myocardial Imaging, ed 1. Hasselt, BSWK, 2006.

18 Kasper DL, Braunwald E, Fauci A, et al: Harrison's Principles of Internal Medicine, ed 16. New York, McGraw-Hill, 2005, p 1346.

$\checkmark 19$ Jessup M, Abraham WT, Casey DE, et al: 2009 focused update: ACCF/AHA Guidelines for the Diagnosis and Management of Heart Failure in Adults: a report of the American College of Cardiology Foundation/American Heart Association Task Force on Practice Guidelines - developed in collaboration with the International Society for Heart and Lung Transplantation. Circulation 2009;119:1977-2016.

-20 Opie LH, Commerford PJ, Gersh BJ, Pfeffer MA: Controversies in ventricular remodelling. Lancet 2006;367:356-367.

$\checkmark 21$ Kiserud T, Acharya G: The fetal circulation. Prenat Diagn 2004;24:1049-1059.

-22 Anderson R, Merup M, Sanchez-Quintana D, Loukas M, Lunkenheimer P: The threedimensional arrangement of the myocytes in the ventricular walls. Clin Anat 2009;22:6476.
23 Sengupta PP, Tajik AJ, Chandrasekaran K, Khandheria BJ: Twist mechanics of the left ventricle: principles and application. JACC Cardiovasc Imaging 2008; 1:366-376.

24 Burns AT, McDonald IG, Thomas JD, Macisaac A, Prior D: Doin' the twist: new tools for an old concept of myocardial function. Heart 2008;94:978-983.

-25 Barker PC, Houle H, Li JS, Miller S, Herlong JR, Camitta MG: Global longitudinal cardiac strain and strain rate for assessment of fetal cardiac function: novel experience with velocity vector imaging. Echocardiography 2009;26:28-36.

26 Sedmera D: Function and form in the developing cardiovascular system. Cardiovasc Res 2011;91:252-259.

27 Tobita K, Garrison JB, Liu LJ, Tinney JP, Keller BB: Three-dimensional myofiber architecture of the embryonic left ventricle during normal development and altered mechanical loads. Anat Rec A Discov Mol Cell Evol Biol 2005;283:193-201.

28 Comas M, Crispi F: Assessment of fetal cardiac function using tissue Doppler techniques. Fetal Diagn Ther, in press.

29 Germanakis I, Gardiner H: Assessment of fetal myocardial deformation using speckle tracking techniques. Fetal Diagn Ther, in press.

30 Godfrey ME, Messing B, Valsky DV, Cohen SM, Yagel S: Mini-review of fetal cardiac function: M-mode and 4D-STIC. Fetal Diagn Ther, in press.

31 Hernandez-Andrade E, Benavides Serralde JA, Cruz-Martinez R, Welsh A: Evaluation of conventional Doppler fetal cardiac function parameters: E/A ratios, outflow tracts and myocardial performance index. Fetal Diagn Ther, in press.

32 Baschat AA, Cosmi E, Bilardo CM, Wolf $\mathrm{H}$, Berg C, Rigano S, Germer U, Moyano D, Turan S, Hartung J, Bhide A, Muller T, Bower S, Nicolaides KH, Thilaganathan B, Gembruch U, Ferrazzi E, Hecher K, Galan H, Harman CR: Predictors of neonatal outcome in early-onset placental dysfunction. Obstet Gynecol 2007;109:253-261.

33 Timmerman E, Clur SA, Pajkrt E, Bilardo CM: First-trimester measurement of the ductus venosus pulsatility index and the prediction of congenital heart defects. Ultrasound Obstet Gynecol 2010;36:668-675.

34 Tei C, Nishimura RA, Seward JB, Tajik AJ: Noninvasive Doppler-derived myocardial performance index: correlation with simultaneous measurements of cardiac catheterization measurements. J Am Soc Echocardiogr 1997;10:169-178.

35 Hernandez-Andrade E, López-Tenorio J, Figueroa-Diesel H, Sanin-Blair J, Carreras E, Cabero L, Gratacos E: A modified myocardial performance (Tei) index based on the use of valve clicks improves reproducibility of fetal left cardiac function assessment. Ultrasound Obstet Gynecol 2005;26:227-232.
6 Cruz-Martinez R, Figueras F, HernandezAndrade E, Oros D, Gratacos E: Changes in myocardial performance index and aortic isthmus and ductus venosus Doppler in term, small-for-gestational age fetuses with normal umbilical artery pulsatility index. Ultrasound Obstet Gynecol 2011;38:400405.

37 Van Mieghem T, Klaritsch P, Done E, et al: Assessment of fetal cardiac function before and after therapy for twin-to-twin transfusion syndrome. Am J Obstet Gynecol 2009; 200:400.e1-401.e7.

38 Yagel S, Silverman NH, Gembruch U: Fetal Cardiology: Embryology, Genetics, Physiology, Echocardiographic Evaluation, Diagnosis and Perinatal Management of Cardiac Diseases, ed 2. New York, Informa Healthcare USA, 2009.

-39 Cikes M, Sutherland GR, Anderson LJ, Bijnens $\mathrm{BH}$ : The role of echocardiographic deformation imaging in hypertrophic myopathies. Nat Rev Cardiol 2010;7:384-396.

40 Carvalho JS, O'Sullivan C, Shinebourne EA et al: Right and left ventricular long-axis function in the fetus using angular M-mode. Ultrasound Obstet Gynecol 2001;18:619-622.

41 Ho CY, Solomon SD: A clinician's guide to tissue Doppler imaging. Circulation 2006; 113:e396-e398.

42 Yu CM, Sanderson JE, Marwick TH, Oh JK: Tissue Doppler imaging a new prognosticator for cardiovascular diseases. J Am Coll Cardiol 2007;49:1903-1914.

43 Comas M, Crispi F, Cruz-Martinez R, Martinez JM, Figueras F, Gratacós E: Usefulness of myocardial tissue Doppler vs conventional echocardiography in the evaluation of cardiac dysfunction in early-onset intrauterine growth restriction. Am J Obstet Gynecol 2010;203:45.e1-45.e7.

44 Van Mieghem T, Giusca S, DeKoninck P, Gucciardo L, Doné E, Hindryckx A, D’Hooge J, Deprest J: Prospective assessment of fetal cardiac function with speckle tracking in healthy fetuses and recipient fetuses of twinto-twin transfusion syndrome. J Am Soc Echocardiogr 2010;23:301-308.

$\checkmark 4$ Comas M, Crispi F, Gómez O, Puerto B, Figueras F, Gratacós E: Gestational age- and estimated fetal weight-adjusted reference ranges for myocardial tissue Doppler indices at 24-41 weeks' gestation. Ultrasound $\mathrm{Ob}$ stet Gynecol 2011;37:57-64.

-46 D’Hooge J, Heimdal A, Jamal F, Kukulski T, Bijnens B, Rademakers F, Hatle L, Suetens P, Sutherland GR: Regional strain and strain rate measurements by cardiac ultrasound: principles, implementation and limitations. Eur J Echocardiogr 2000;1:154-170.

47 Simpson J: Speckle tracking for the assessment of fetal cardiac function. Ultrasound Obstet Gynecol 2011;37:133-134.

48 Welsh AW, Meriki N: Technical considerations for measurement of the fetal left modified myocardial performance index. Fetal Diagn Ther 2012;31:76-80. 
\49 Nagueh SF, Middleton KJ, Kopelen HA, Zoghbi WA, Quiñones MA: Doppler tissue imaging: a noninvasive technique for evaluation of left ventricular relaxation and estimation of filling pressures. J Am Coll Cardiol 1997;30:1527-1533.

-50 Martinez JM, Comas M, Borrell A, Bennasar M, Gómez O, Puerto B, Gratacós E: Abnormal first-trimester ductus venosus blood flow: a marker of cardiac defects in fetuses with normal karyotype and nuchal translucency. Ultrasound Obstet Gynecol 2010;35: 267-272.

-51 Pereira S, Ganapathy R, Syngelaki A, Maiz N, Nicolaides KH: Contribution of fetal tricuspid regurgitation in first-trimester screening for major cardiac defects. Obstet Gynecol 2011;117:1384-1391.

-52 Wieczorek A, Hernandez-Robles J, Ewing L, Leshko J, Luther S, Huhta J: Prediction of outcome of fetal congenital heart disease using a cardiovascular profile score. Ultrasound Obstet Gynecol 2008;31:284-288.

- 53 Larsen LU, Petersen OB, Norrild K, Sorensen K, Uldbjerg N, Sloth E: Strain rate derived from color Doppler myocardial imaging for assessment of fetal cardiac function. Ultrasound Obstet Gynecol 2006;27:210-213.

54 Willruth AM, Geipel A, Berg C, Fimmers R, Gembruch U: Assessment of fetal global and regional ventricular function in congenital heart disease using a novel feature tracking technique. Ultraschall Med 2011, E-pub ahead of print.

55 Germanakis I, Matsui H, Gardiner HM: Myocardial strain abnormalities in fetal congenital heart disease assessed by speckle tracking echocardiography. Fetal Diagn Ther, in press.

-56 McElhinney DB, Vogel M, Benson CB, Marshall AC, Wilkins-Haug LE, Silva V, Tworetzky W: Assessment of left ventricular endocardial fibroelastosis in fetuses with aortic stenosis and evolving hypoplastic left heart syndrome. Am J Cardiol 2010;106:17921797.

57 Friedman KG, Margossian R, Graham DA, Harrild DM, Emani SM, Wilkins-Haug LE, McElhinney DB, Tworetzky W: Postnatal left ventricular diastolic function after fetal aortic valvuloplasty. Am J Cardiol 2011;108: 556-560.

-58 Pedra SR, Hornberger LK, Leal SM, Taylor GP, Smallhorn JF: Cardiac function assessment in patients with family history of nonhypertrophic cardiomyopathy: a prenatal and postnatal study. Pediatr Cardiol 2005; 26:543-552.

59 Pedra SR, Smallhorn JF, Ryan G, Chitayat D, Taylor GP, Khan R, Abdolell M, Hornberger LK: Fetal cardiomyopathies: pathogenic mechanisms, hemodynamic findings, and clinical outcome. Circulation 2002;106:585591.
60 Lisowski LA, Verheijen PM, Copel JA, Kleinman CS, Wassink S, Visser GH, Meijboom EJ: Congenital heart disease in pregnancies complicated by maternal diabetes mellitus: an international clinical collaboration, literature review, and meta-analysis. Herz 2010;35:19-26.

61 Gardiner HM, Pasquini L, Wolfenden J, Kulinskaya E, Li W, Henein M: Increased periconceptional maternal glycated haemoglobin in diabetic mothers reduces fetal long axis cardiac function. Heart 2006;92:11251130.

62 Gandhi JA, Zhang XY, Maidman JE: Fetal cardiac hypertrophy and cardiac function in diabetic pregnancies. Am J Obstet Gynecol 1995;173:1132-1136.

63 Zielinsky P, Piccoli AL Jr, Teixeira L, Gus EI, Mânica JL, Satler F, Vaz H, Nicoloso LH, Luchese S, Sheid M, Marcantonio S, Hatém D: Pulmonary vein pulsatility in fetuses of diabetic mothers: prenatal Doppler echocardiographic study. Arq Bras Cardiol 2003;81: 604-607.

64 Rizzo G, Arduini D, Romanini C: Accelerated cardiac growth and abnormal cardiac flow in fetuses of type I diabetic mothers. Obstet Gynecol 1992;80:369-376.

65 Zielinsky P, Marcantonio S, Nicoloso LH, et al: Ductus venosus flow and myocardial hypertrophy in fetuses of diabetic mothers. Arq Bras Cardiol 2004;83:51-56, 45-50.

-66 Stuart A, Amer-Wahlin I, Gudmundsson S, Marsal K, Thuring A, Kallen K: Ductus venosus blood flow velocity waveform in diabetic pregnancies. Ultrasound Obstet Gynecol 2010;36:344-349.

67 Turan S, Turan OM, Miller J, Harman C, Reece EA, Baschat AA: Decreased fetal cardiac performance in the first trimester correlates with hyperglycemia in pre-gestational maternal diabetes. Ultrasound Obstet Gynecol 2011;38:325-331.

68 Oran B, Cam L, Başpinar O, Baysal T, Reisli I, Peru H, Karaaslan S, Koç H, Gürbilek M: Cardiac troponin-I in the serum of infants of diabetic mothers. Cardiol Young 2003; 13: 248-252.

69 Kozák-Bárány A, Jokinen E, Kero P, Tuominen J, Rönnemaa T, Välimäki I: Impaired left ventricular diastolic function in newborn infants of mothers with pregestational or gestational diabetes with good glycemic control. Early Hum Dev 2004;77:13-22.

-70 Manderson JG, Mullan B, Patterson CC, Hadden DR, Traub AI, McCance DR: Cardiovascular and metabolic abnormalities in the offspring of diabetic pregnancy. Diabetologia 2002;45:991-996.

71 Alberry M, Soothill P: Management of fetal growth restriction. Arch Dis Child Fetal Neonatal Ed 2007;92:62-67.

72 Figueras F, Puerto B, Martinez JM, Cararach V, Vanrell JA: Cardiac function monitoring of fetuses with growth restriction. Eur J Obstet Gynecol Reprod Biol 2003;110:159-163.
73 Kiserud T, Ebbing C, Kessler J, Rasmussen S: Fetal cardiac output, distribution to the placenta and impact of placental compromise. Ultrasound Obstet Gynecol 2006;28:126-136.

74 Larsen LU, Sloth E, Petersen B, et al: Systolic myocardial velocity alterations in the growth-restricted fetus with cerebroplacental redistribution. Ultrasound Obstet Gynecol 2009;34:62-67.

75 Bilardo CM, Wolf H, Stigter RH, Ville Y, Baez E, Visser CH, Hecher K: Relationship between monitoring parameters and perinatal outcome in severe, early intrauterine growth restriction. Ultrasound Obstet Gynecol 2004;23:119-125.

76 Makikallio K, Vuolteenaho O, Jouppila P, Rasanen J: Ultrasonographic and biochemical markers of human fetal cardiac dysfunction in placental insufficiency. Circulation 2002;105:2058-2063.

77 Watanabe S, Hashimoto I, Saito K, et al: Characterization of ventricular myocardial performance in the fetus by tissue Doppler imaging. Circ J 2009;73:943-947.

-78 Naujorks AA, Zielinsky P, Beltrame A, et al Myocardial tissue Doppler assessment of diastolic function in the growth-restricted fetus. Ultrasound Obstet Gynecol 2009;34:68-73.

79 Niewiadomska-Jarosik K, Lipecka-Kidawska E, Kowalska-Koprek U, et al: Assessment of cardiac function in fetuses with intrauterine growth retardation using the Tei index (in Polish). Med Wieku Rozwoj 2005;9:153160.

80 Larsen LU, Petersen OB, Sloth E, Uldbjerg N Color Doppler myocardial imaging demonstrates reduced diastolic tissue velocity in growth retarded fetuses with flow redistribution. Eur J Obstet Gynecol Reprod Biol 2011;155:140-145.

81 Girsen A, Ala-Kopsala M, Makikallio K, Vuolteenaho O, Rasanen J: Cardiovascular hemodynamics and umbilical artery $\mathrm{N}$-terminal peptide of proB-type natriuretic peptide in human fetuses with growth restriction. Ultrasound Obstet Gynecol 2007;29: 296-303.

82 Hernandez-Andrade E, Crispi F, BenavidesSerralde JA, Plasencia W, Diesel HF, Eixarch E, Acosta-Rojas R, Figueras F, Nicolaides K, Gratacós E: Contribution of the myocardial performance index and aortic isthmus blood flow index to predicting mortality in preterm growth-restricted fetuses. Ultrasound Obstet Gynecol 2009;34:430-436.

83 Baschat AA: Fetal growth restriction: from observation to intervention. J Perinat Med 2010;38:239-246.

84 Cruz-Lemini M, Crispi F, Van Mieghem T, Pedraza D, Cruz-Martínez R, Acosta-Rojas R, Figueras F, Parra-Cordero M, Deprest J, Gratacós E: Risk of perinatal death in earlyonset intrauterine growth restriction according to gestational age and cardiovascular Doppler indices: a multicenter study. Fetal Diagn Ther, in press. 
85 Soothill PW, Bobrow CS, Holmes R: Small for gestational age is not a diagnosis. Ultrasound Obstet Gynecol 1999;13:225-228.

-86 Illa M, Coloma JL, Eixarch E, Meler E, Iraola A, Gardosi J, Gratacós E, Figueras F: Growth deficit in term small-for-gestational fetuses with normal umbilical artery Doppler is associated with adverse outcome. J Perinat Med 2009;37:48-52.

-87 Figueras F, Oros D, Cruz-Martinez R, Padilla N, Hernandez-Andrade E, Botet F, CostasMoragas C, Gratacos E: Neurobehavior in term, small-for-gestational age infants with normal placental function. Pediatrics 2009; 124:e934-e941.

-88 Eixarch E, Meler E, Iraola A, Illa M, Crispi F, Hernandez-Andrade E, Gratacos E, Figueras F: Neurodevelopmental outcome in 2-yearold infants who were small-for-gestational age term fetuses with cerebral blood flow redistribution. Ultrasound Obstet Gynecol 2008;32:894-899.

\$89 Crispi F, Bijnens B, Figueras F, Bartrons J, Eixarch E, Le Noble F, Ahmed A, Gratacós E: Fetal growth restriction results in remodeled and less efficient hearts in children. Circulation 2010;121:2427-2436.

-90 Tintu A, Rouwet E, Verlohren S, Brinkmann J, Ahmad S, Crispi F, van Bilsen M, Carmeliet P, Staff AC, Tjwa M, Cetin I, Gratacos E, Hernandez-Andrade E, Hofstra L, Jacobs M, Lamers WH, Morano I, Safak E, Ahmed A, le Noble F: Hypoxia induces dilated cardiomyopathy in the chick embryo: mechanism, intervention, and long-term consequences. PLoS One 2009;4:e5155.

-91 Chaiworapongsa T, Espinoza J, Yoshimatsu $\mathrm{J}$, et al: Subclinical myocardial injury in small-for-gestational-age neonates. J Matern Fetal Neonatal Med 2002;11:385-390.

$\$ 92$ Comas M, Crispi F, Cruz-Martinez R, Figueras F, Gratacos E: Tissue Doppler echocardiographic markers of cardiac dysfunction in small-for-gestational age fetuses. Am J Obstet Gynecol 2011;205:57.e1-57.e6.

93 Cruz-Martinez R, Figueras F, HernandezAndrade E, Oros D, Gratacos E: Changes in myocardial performance index and aortic isthmus and ductus venosus Doppler in term, small-for-gestational age fetuses with normal umbilical artery pulsatility index. Ultrasound Obstet Gynecol 2011;38:400405.

-94 Quintero RA, Morales WJ, Allen MH, Bornick PW, Johnson PK, Kruger M: Staging of twin-twin transfusion syndrome. J Perinatol 1999; 19:550-555.

\$5 Karatza AA, Wolfenden JL, Taylor MJ, Wee L, Fisk NM, Gardiner HM: Influence of twin-twin transfusion syndrome on fetal cardiovascular structure and function: prospective case-control study of 136 monochorionic twin pregnancies. Heart 2002;88:271277.
96 Stirnemann JJ, Mougeot M, Proulx F, Nasr B, Essaoui M, Fouron JC, Ville Y: Profiling fetal cardiac function in twin-twin transfusion syndrome. Ultrasound Obstet Gynecol 2010;35:19-27.

-97 Gratacós E, Van Schoubroeck D, Carreras E, Devlieger R, Roma E, Cabero L, Deprest J: Impact of laser coagulation in severe twin-twin transfusion syndrome on fetal Doppler indices and venous blood flow volume. Ultrasound Obstet Gynecol 2002; 20:125-130.

98 Gungor S, Glosemeyer P, Huber A, Hecher $\mathrm{K}$, Baschat AA: Umbilical venous volume flow in twin-twin transfusion syndrome. Ultrasound Obstet Gynecol 2008;32:800806.

-99 Zosmer N, Bajoria R, Weiner E, Rigby M, Vaughan J, Fisk NM: Clinical and echographic features of in utero cardiac dysfunction in the recipient twin in twin-twin transfusion syndrome. Br Heart J 1994;72: 74-79.

100 Szwast A, Tian Z, McCann M, Donaghue D, Bebbington M, Johnson M, Wilson RD, Rychik J: Impact of altered loading conditions on ventricular performance in fetuses with congenital cystic adenomatoid malformation and twin-twin transfusion syndrome. Ultrasound Obstet Gynecol 2007;30:4046.

101 Bajoria R, Ward S, Chatterjee R: Natriuretic peptides in the pathogenesis of cardiac dysfunction in the recipient fetus of twintwin transfusion syndrome. Am J Obstet Gynecol 2002;186:121-127.

102 Michelfelder E, Gottliebson W, Border W, Kinsel M, Polzin W, Livingston J, Khoury P, Crombleholme T: Early manifestations and spectrum of recipient twin cardiomyopathy in twin-twin transfusion syndrome: relation to Quintero stage. Ultrasound Obstet Gynecol 2007;30:965-971.

103 Divanović A, Cnota J, Ittenbach R, Tan X, Border W, Crombleholme T, Michelfelder E: Characterization of diastolic dysfunction in twin-twin transfusion syndrome: association between Doppler findings and ventricular hypertrophy. J Am Soc Echocardiogr 2011;24:834-840.

104 Raboisson MJ, Fouron JC, Lamoureux J, Leduc L, Grignon A, Proulx F, Gamache S: Early intertwin differences in myocardial performance during the twin-to-twin transfusion syndrome. Circulation 2004; 110:3043-3048.

105 Fesslova V, Villa L, Nava S, Mosca F, Nicolini U: Fetal and neonatal echocardiographic findings in twin-twin transfusion syndrome. Am J Obstet Gynecol 1998;179: 1056-1062.

106 Nizard J, Bonnet D, Fermont L, Ville Y: Acquired right heart outflow tract anomaly without systemic hypertension in recipient twins in twin-twin transfusion syndrome. Ultrasound Obstet Gynecol 2001;18:669672 .
107 Gray PH, Cincotta R, Chan FY, Soong B: Perinatal outcomes with laser surgery for twin-twin transfusion syndrome. Twin Res Hum Genet 2009;9:438-443.

108 Halvorsen CP, Bilock SL, Pilo C, Sonesson SE, Norman M: Childhood cardiac function after twin-to-twin transfusion syndrome: a 10-year follow up. Acta Paediatr 2009;98:1468-1474.

109 Takahashi H, Takahashi S, Tsukamoto K, Ito Y, Nakamura T, Hayashi S, Sago H: Persistent pulmonary hypertension of the newborn in twin-twin transfusion syndrome following fetoscopic laser surgery. J Matern Fetal Neonatal Med 2011, E-pub ahead of print.

110 Tolosa JE, Zoppini C, Ludomirsky A, et al: Fetal hypertension and cardiac hypertrophy in the discordant twin syndrome. Am J Obstet Gynecol 1993;168:292.

111 Mercanti I, Boivin A, Wo B, Vlieghe V, Le Ray C, Audibert F, Fouron JC, Leduc L, Nuyt AM: Blood pressures in newborns with twin-twin transfusion syndrome. J Perinatol 2011;31:417-424.

112 Cheung YF, Taylor MJ, Fisk NM, Redington AN, Gardiner HM: Fetal origins of reduced arterial distensibility in the donor twin in twin-twin transfusion syndrome. Lancet 2000;355:1157-1158.

113 Gardiner HM, Taylor MJ, Karatza A, Vanderheyden T, Huber A, Greenwald SE, Fisk NM, Hecher K: Twin-twin transfusion syndrome: the influence of intrauterine laser photocoagulation on arterial distensibility in childhood. Circulation 2003;107:19061911.

114 Stressig R, Fimmers R, Eising K, Gembruch U, Kohl T: Preferential streaming of the ductus venosus and inferior caval vein towards the right heart is associated with left heart underdevelopment in human fetuses with left-sided diaphragmatic hernia. Heart 2010;96:1564-1568.

115 Messing B, Cohen SM, Valsky DV, Shen O, Rosenak D, Lipschuetz M, Yagel S: Fetal heart ventricle mass obtained by STIC acquisition combined with inversion mode and VOCAL. Ultrasound Obstet Gynecol 2011;38:191-197.

116 Kalache KD, Mkhitaryan M, Bamberg C, Roehr CC, Wauer R, Mau H, Bollmann R: Isolated left-sided congenital diaphragmatic hernia: cardiac axis and displacement before fetal viability has no role in predicting postnatal outcome. Prenat Diagn 2007;27: 322-326.

117 Stefanutti G, Filippone M, Tommasoni N, Midrio P, Zucchetta P, Moreolo GS, Toffolutti T, Baraldi E, Gamba P: Cardiopulmonary anatomy and function in long-term survivors of mild to moderate congenital diaphragmatic hernia. J Pediatr Surg 2004; 39:526-531. 
118 Aggarwal S, Stockman PT, Klein MD, Natarajan G: The right ventricular systolic to diastolic duration ratio: a simple prognostic marker in congenital diaphragmatic hernia? Acta Paediatr 2011;100:1315-1318.

119 Cua CL, Cooper AL, Stein MA, Corbitt RJ, Nelin LD: Tissue Doppler changes in three neonates with congenital diaphragmatic hernia. ASAIO J 2009;55:417-419.

120 Baptista MJ, Rocha G, Clemente F, Azevedo LF, Tibboel D, Leite-Moreira AF, Guimarães $\mathrm{H}$, Areias JC, Correia-Pinto J: Nterminal-pro-B type natriuretic peptide as a useful tool to evaluate pulmonary hypertension and cardiac function in $\mathrm{CDH}$ infants. Neonatology 2008;94:22-30.

121 Mahle WT, Rychik J, Tian ZY, Cohen MS, Howell LJ, Crombleholme TM, Flake AW, Adzick NS: Echocardiographic evaluation of the fetus with congenital cystic adenomatoid malformation. Ultrasound Obstet Gynecol 2000;16:620-624.

122 Szwast A, Tian Z, McCann M, Donaghue D, Bebbington M, Johnson M, Wilson RD, Rychik J: Impact of altered loading conditions on ventricular performance in fetuses with congenital cystic adenomatoid malformation and twin-twin transfusion syndrome. Ultrasound Obstet Gynecol 2007;30:4046.

123 Lee MY, Won HS, Hyun MK, Lee HY, Shim JY, Lee PR, Kim A: Perinatal outcome of sacrococcygeal teratoma. Prenat Diagn 2011; 31:1217-1221.

-124 Heling KS, Chaoui R, Bollmann R: Prenatal diagnosis of an aneurysm of the vein of Galen with three-dimensional color power angiography. Ultrasound Obstet Gynecol 2000;15:333-336.
125 Berg C, Kamil D, Geipel A, Kohl T, Knöpfle G, Hansmann M, Gembruch U: Absence of ductus venosus: importance of umbilical venous drainage site. Ultrasound Obstet Gynecol 2006;28:275-281.

126 Acherman RJ, Rollins RC, Castillo WJ, Evans WN: Stenosis of alternative umbilical venous pathways in absence of the ductus venosus. J Ultrasound Med 2010;29:12271231.

127 Rychik J, McCann M, Tian Z, Bebbington M, Johnson MP: Fetal cardiovascular effects of lower urinary tract obstruction with giant bladder. Ultrasound Obstet Gynecol 2010;36:682-686.

128 Dickinson JE, Sharpe J, Warner TM, Nathan EA, D'Orsogna L: Childhood cardiac function after severe maternal red cell isoimmunization. Obstet Gynecol 2010;116: 851-857.

129 Lamont RF, Sobel JD, Vaisbuch E, Kusanovic JP, Mazaki-Tovi S, Kim SK, Uldbjerg N, Romero R: Parvovirus B19 infection in human pregnancy. BJOG 2011;118:175186.

130 Fishman SG, Pelaez LM, Baergen RN, Carroll SJ: Parvovirus-mediated fetal cardiomyopathy with atrioventricular nodal disease. Pediatr Cardiol 2011;32:84-86.

131 Romero R, Espinoza J, Gonçalves LF, Gomez R, Medina L, Silva M, Chaiworapongsa T, Yoon BH, Ghezzi F, Lee W, Treadwell M, Berry SM, Maymon E, Mazor M, DeVore G: Fetal cardiac dysfunction in preterm premature rupture of membranes. J Matern Fetal Neonatal Med 2004;16:146-157.

132 Di Naro E, Cromi A, Ghezzi F, Giocolano A, Caringella A, Loverro G: Myocardial dysfunction in fetuses exposed to intraamniotic infection: new insights from tissue Doppler and strain imaging. Am J Obstet Gynecol 2010;203:459.e1-459.e7.
133 Letti Müller AL, Barrios Pde M, Kliemann LM, Valério EG, Gasnier R, Magalhães JA: Tei index to assess fetal cardiac performance in fetuses at risk for fetal inflammatory response syndrome. Ultrasound $\mathrm{Ob}$ stet Gynecol 2010;36:26-31.

134 Calda P, Brestak M, Tomek V, Ostadal B, Sonek J: Left ventricle shortening fraction: a comparison between euploid and trisomy 21 fetuses in the first trimester. Prenat Diagn 2010;30:368-371.

135 Clur SA, Oude Rengerink K, Ottenkamp J, Bilardo CM: Cardiac function in trisomy 21 fetuses. Ultrasound Obstet Gynecol 2011; 37:163-171.

136 Berenson GS: Childhood risk factors predict adult risk associated with subclinical cardiovascular disease: the Bogalusa Heart Study. Am J Cardiol 2002;90:3L-7L.

137 Palinski W, Napoli C: Impaired fetal growth, cardiovascular disease, and the need to move on. Circulation 2008;117:341-343.

138 Rinaudo P, Wang E: Fetal programming and metabolic syndrome. Annu Rev Physiol 2012;74:107-130.

139 Kavey RE, Allada V, Daniels SR, Hayman LL, McCrindle BW, Newburger JW, Parekh RS, Steinberger J: Cardiovascular risk reduction in high-risk pediatric patients: a scientific statement from the American Heart Association Expert Panel on Population and Prevention Science; the Councils on Cardiovascular Disease in the Young, Epidemiology and Prevention, Nutrition, Physical Activity and Metabolism, High Blood Pressure Research, Cardiovascular Nursing, and the Kidney in Heart Disease; and the Interdisciplinary Working Group on Quality of Care and Outcomes Research: endorsed by the American Academy of Pediatrics. Circulation 2006; 114: 2710-2738. 